\title{
A Desigualdade é Vermelha?
}

\author{
Is inequity red? \\ Liliane Machado ${ }^{1}$ \\ http://dx.doi.org/10.5216/cei.v14i2.22451
}

\begin{abstract}
Resumo
Trata-se de uma análise do filme Lanternas vermelhas, sob uma perspectiva multidisciplinar, que engloba os estudos de gênero, a cultura da mídia e a psicanálise com o intuito de investigar as relações de poder nas quais estão envolvidos três esposas e o marido. O simbolismo cinematográfico permitiu-nos verificar a existência da assimetria entre os gêneros, a divisão rígida entre o público e o privado e a resistência débil das mulheres frente ao poderio masculino. Dessa forma, ressaltou-se as consequiências emocionais e sociais que advém paras as personagens, estabelecendo-se por fim, uma conexão com a realidade de um expressivo número de relacionamentos conjugais na sociedade atual.
\end{abstract}

Palavras-chaves: Lanternas Vermelhas. Cultura da Mídia. Estudos de Gênero. Psicanálise. Poder.

\begin{abstract}
This paper consists of an analysis of the film Raise the Red Lantern under a multidisciplinary perspective, which embodies gender studies, media culture and psychoanalysis, with the purpose of investigating the power relations in which the three wives and the husband and involved. The cinematographic symbolism enabled the verification of the existence of an asymmetry between the genders, a rigid division between private and public, and a feeble resistance of women towards male authority. Thus, the emotional and social consequences that befall the female characters have been highlighted by then establishing a connection to the reality of an expressive number of conjugal relationships in current society.
\end{abstract}

Keywords: Raise the Red Lantern. Media Culture. Gender Studies. Psychoanalysis. Power.

\section{Introdução}

Optamos por trabalhar com o filme Lanternas Vermelhas, produção de 1991, dirigida pelo chinês Zhang Yimou, por acreditarmos que a obra nos servirá de emblema para que possamos refletir sobre as relações de gênero. A história é baseada no livro Esposas e Concubinas, de Su Tong, ambientada na China, nos anos 1920. É, sem dúvidas, uma das mais belas do diretor, a qual, mesmo realizada há quase 20 anos, continua capaz de causar uma experiência estética difícil de ser

\footnotetext{
${ }^{1}$ Professora do Programa Stricto Sensu em Comunicação da Universidade Católica de Brasília. Desenvolve pesquisas concernentes aos seguintes temas: jornalismo público, jornalismo e sociedade, cinema, desenho animado, feminismo, gênero, representações sociais, imaginário e análise de discurso. Também edita a Revista Diálogos, periódico científico que aborda a pesquisa e extensão em âmbito nacional.
} 
esquecida. Mais que isso, entretanto, causa-nos espanto e desperta-nos o desejo de avaliá-la, sob a luz das teorizações de gênero e dos estudos feministas.

Em ação, vemos no filme, um senhor e suas quatro esposas, imersos numa estrutura familiar semifeudal. As mulheres estão restritas ao espaço doméstico, e o senhor detém o domínio de vida e de morte sobre elas. O filme começa quando o senhor contrai núpcias pela quarta vez. A escolhida é Songliang (vivida pela atriz Gong Li, atriz de vários filmes do diretor), ex-universitária, que foi obrigada a abandonar os estudos e a casar-se para salvar a família da falência financeira.

Aparentemente, Songliang tem conhecimentos e impetuosidade suficientes para enfrentar a situação de opressão a que ela e as outras esposas estão submetidas. Aos poucos, porém, vemos a heroína mergulhar na disputa que se trava pelo poder de ser a escolhida pelo senhor a cada noite, em um elaborado ritual, que deixa as mulheres à mercê do desejo masculino. Queremos investigar o que impede a jovem de contrapor-se à estrutura hierárquica que reina na casa. Partimos da hipótese de que não são apenas as possibilidades de punição às infratoras das normas o que a atormenta e, sim, a estrutura social e as amarras internas que a levam a assumir a posição de submissão perante a figura masculina.

Tomaremos o filme como uma metáfora possível das relações de gênero, as quais, em certa medida, persistem, na sociedade brasileira contemporânea, em diversos estratos sociais, desde que se observe que a violência simbólica de casamentos que terminam em morte literal, ou não, das mulheres ainda é real e incomoda enormemente a todos que se dedicam ao assunto. O roteiro da obra é rico em alegorias que expõem o confronto entre o feminino e o masculino. Considere-se, inicialmente, a oposição tradicional entre o público e o privado. Esses dois espaços delimitam o alcance de poder que cada um dos gêneros dispõe. O senhor move-se na vida pública, onde exerce relações de negócios com pessoas de origens diversas enquanto que as mulheres estão confinadas á casa, às intrigas amorosas e aos conflitos domésticos.

Outro aspecto que iremos abordar é a sedução que o exercício do poder provoca. Há uma acirrada disputa entre as mulheres para ser a escolhida pelo senhor para dormir com ele, opção que lhes possibilita uma série de privilégios no espaço doméstico. Para investigarmos este ponto, tentaremos dialogar com teóricos que buscam compreender o exercício do poder e da autonomia.

A análise, no entanto, não poderia prescindir da observação acerca do que ocorre no interior das personagens, envolvidas em um conflito que diminui-lhes a autoestima e as incentiva à maledicência mútua. Iremos em busca dos pressupostos psicanalíticos de formação da identidade e 
da emergência do sujeito,elaborados por Freud e Lacan e, posteriormente, retomados por estudiosas do gênero, como Gayle Rubin e Kaja Silvermann, com o objetivo de implementar a interdisciplinaridade entre a antropologia, psicanálise e comunicação social.

Os estudos sobre os produtos midiáticos, tais como filmes, novelas e seriados integram uma das vertentes das teorias comunicacionais, identificadas sob a noção de cultura da mídia e/ou estudos culturais. Kellner (2001,p.53) argumenta que é fundamental que os analistas consigam articular mídia/cultura/comunicação para que se consiga interpretar a cultura e a sociedade em termos de relações de poder. Acrescenta, ainda, a necessidade de se integrar a tais estudos a noção de multiculturalismo:

preconizamos (...) a necessidade de mobilizar as teorias marxistas de classe, os conceitos feministas de sexo, e as teorias multiculturalistas de raça, etnia, preferência sexual, nacionalidades, etc. a fim de de expressar toda a gama de representações de identidade, dominação e resistência que estruturam o terreno da cultura da mídia. (Kellner, 2001, p.76).

Dessa forma, cremos ampliar as possibilidades de compreensão acerca dos conflitos existentes no filme, os quais, aparentemente, justificam a imutabilidade da relação entre o masculino e o feminino, imersos em uma relação heterossexual assimétrica. Concomitantemente, exploraremos um produto comunicacional de enorme relevância, que alcançou considerável público entre os fãs do cinema chinês e, particularmente de Yimou, que continua em plena atividade, constantemente retornando ao tema dos conflitos entre os gêneros, permeados pelas disputas de poder $^{2}$.

\section{Três atos de uma tragédia}

A narrativa explora a lenta transformação que vivencia Songliang, desde o momento em que chega à casa do marido até o seu fim trágico. Ela surge, inicialmente, como uma personagem forte e inteligente, de atitude despojadas. Aos poucos, porém, sucumbe à disputa que se trava entre as mulheres da casa. A heroína perde cada um dos principais lances da disputa, o que a fragiliza emocionalmente de uma maneira inexorável. Concomitantemente, isola-se em um mundo particular e segue a sina de muitas mulheres que enlouqueceram diante de uma situação opressiva, para a qual

\footnotetext{
${ }^{2}$ Veja uma de suas mais recentes, A Maldição da Flor Dourada, também estrelado por Gong Lee, cuja história envolve as disputas entre um rei e uma rainha e a recusa desta em submeter-se aos caprichos do soberano. YIMOU, Zhang. 2008, Distribuidor: Sony Pictures.
} 
não vem uma saída possível. Passemos, em seguida, à descrição e análise dos três atos que, a nosso ver, compõem a trama, os quais serão entremeados pela análise das relações de gênero.

\section{As esposas}

O que poderíamos chamar de primeiro ato da narrativa compõe-se da apresentação da personagem central; da sua incorporação ao clã dos Chen e da descrição do cotidiano da casa: rituais, normas, segredos, conflitos.

O primeiro diálogo do filme, anterior à exibição dos créditos, se dá entre Songliang e sua madrasta. A câmera está parada diante do rosto jovem e belo da atriz, em primeiro plano, captandolhe as nuances das expressões faciais. Não se revela a face da interlocutora. A conversa está pelo meio e a primeira frase de Songliang é - Basta, irei casar-me! mais tarde, compreenderemos que ela é órfã e que foi obrigada pela madrasta a ceder a pressão do casamento para salvar a família da ruína financeira.

A madrasta pergunta-lhe com quem irá casar-se e Songliang avisa que será com um ricaço, ao que responde a madrasta: - Case-se com um ricaço e será sempre sua concubina! ao que ela responde: - Tudo bem, não é essa a sina da mulher? a decisão expressa um misto de fatalismo e revolta. Ela é uma rebelde, capaz de perceber as injustiças, entretanto, não é sagaz o suficiente para conseguir contrapor-se às normas.

Movida pelo fatalismo do que acredita ser a condição das mulheres, chega à casa do esposo. A câmera é colocada sob o seu ponto de vista e, assim, percebemos, junto com a personagem, as dimensões do local, que lembra um castelo e o muro que o rodeia de ponta a ponta, separando-o do mundo exterior. Songliang, por sua vez, está vestida de maneira informal, tem uma pequena mala sob o braço e chega caminhando, já que dispensara a liteira. Ela parece forte e segura frente à ostentação e sisudez do castelo.

Logo que adentra o recinto tem início o ritual de suas núpcias. Homens acendem lanternas vermelhas na porta dos seus aposentos, uma velha criada massageia-lhe os pés, trocam-lhe o vestido, penteiam-lhe os cabelos. Assim, tem início a transformação de Songliang. Quando o marido chega, ele lhe informa que a massagem é para que as mulheres tenham os pés fortes e possam servir melhor ao marido. No meio da noite o casal é acordado pelos criados que avisam que a terceira esposa está doente e que exige a presença do marido. Ele sai e imediatamente as lanternas 
são transferidas para a casa da outra. Songliang olha-se no espelho e chora. Nesse momento ela sente que é apenas a quarta esposa. Sua identidade anterior é desprezada pela sua nova família.

Trabalho a noção de identidade segundo a vertente abordada por Hall, que a utiliza

Para significar o ponto de encontro, o ponto de sutura, entre, por um lado, os discursos e as práticas que tentam nos 'interpelar', nos falar ou nos convocar para que assumamos nossos lugares como os sujeitos sociais de discursos particulares e, por outro lado, os processos que produzem subjetividades, que nos constroem como sujeitos aos quais se pode 'falar'. (Hall, 2000 ,p.111-112).

As práticas cotidianas do novo lar de nossa heroína não deixam dúvidas sobre sua posição: servir ao marido, conformar-se aos seus desejos, aceitar suas ordens. O choro inicial pode ser considerado uma sujeição ao processo de subjetivação a que estará submetida doravante? Sua existência anterior não contará para nada?

No dia seguinte, ela é apresentada às demais esposas. A primeira é idosa e formal. A segunda aparenta afabilidade e expressa o desejo de ajudar-lhe a compreender o seu novo mundo. Explica que, se for a escolhida pelo senhor noites seguidas, em breve, passará a mandar na casa. A terceira é a mais jovem e mais bela. Uma ex-cantora de ópera com quem se indispõe de imediato.

A cada manhã as esposas têm que aguardar à porta de seus aposentos o anúncio feito pelos criados sobre quem será a escolhida da noite. Em seguida, são colocadas lanternas à sua porta. Passam-se os dias e Songliang é vista caminhando sozinha. A segunda esposa percebe sua solidão, aproxima-se e alerta-lhe que não é bom que fique muitos dias sem massagem nos pés. Songliang aponta-lhe a torre e pergunta-lhe o que abriga ali. A outra explica que se trata da casa da Morte, onde várias mulheres de gerações passadas foram mortas. Pede-lhe, em seguida: - nunca vá lá e nunca comente sobre isso com ninguém.

O breve diálogo delimita, a nosso ver, o fim do primeiro ato. Façamos uma interrupção no relato da história para que analisemos o que ocorreu até então. Quando dialoga com a madrasta e comenta que a sina da mulher é ser a concubina do marido, Songliang expressa um comentário crítico sobre a condição social das mulheres, atitude, aparentemente positiva. De acordo com Stort, a rebeldia é o pressuposto de qualquer ato criativo. "É a responsável pela criação da cultura e é também o único mecanismo pelo qual a personalidade mantém-se integral”. (STORT, 1993, p.56). Porém, a observação crítica de Songliang não a induz a contrapor-se ao que lhe está reservado socialmente. Ao contrário, ao decidir-se por um casamento, com um ricaço, submete-se às normas. Seria esse um sinal de sua debilidade emocional e intelectual? 
Durante séculos, um dos argumentos usados pelo discurso médico para explicar as diferenças existentes entre os gêneros foi retirado da biologia. O corpo, sob essa perspectiva, seria um fator determinante que comprovaria tanto a fragilidade física quanto intelectual das mulheres frente aos homens. Entretanto, sob a perspectiva dos estudos feministas e de gênero, essa assertiva é uma tentativa de naturalização dos corpos, uma falácia que oculta um determinismo míope. Butler observa que " 0 fato de o pênis, de a vagina, de os seios e assim por diante serem denominados partes sexuais corresponde tanto a uma restrição do corpo erógeno a essas partes quanto a uma fragmentação do corpo como um todo”. (BUTLER, 2003, p.167).

Butler afirma que "chegar a ser gênero é um processo impulsivo, ainda que cuidadoso, de interpretar uma realidade cultural carregada de sanções, tabus e prescrições” (1994, p.198). Na sociedade retratada pelo filme de Yimou percebem-se as delimitações a que estão expostas as mulheres: casarem-se, servirem aos maridos, evitarem questionamentos de qualquer ordem e submeterem-se às leis mais sórdidas, até mesmo, a de serem mortas por desobediência.

O inconformismo da heroína é motivado, antes, por sua sensibilidade e rebeldia intuitiva do que propriamente por uma elaboração intelectual, capaz de levá-la a contrapor-se efetivamente aos dogmas sociais e morais. Songliang é vulnerável às adversidades. Ao penetrar no mundo fechado do castelo do marido, onde as instâncias do público e do privado estão profundamente cingidas, a vulnerabilidade amplia-se e ela começa a desmoronar.

Só os homens têm contato com o mundo externo. Quando deixa a casa o marido sabe que suas ordens serão cumpridas rigorosamente pelos criados. As mulheres vigiam-se umas às outras e, qualquer comportamento diferente, pode resultar em intrigas. É o que ocorre com a terceira esposa, que recebe visitas masculinas para jogos de baralho, o que passa a ser motivo de comentários maldosos por parte das outras bem como da criadagem.

Rosaldo argumenta que “o status feminino será mais baixo nas sociedades onde há uma firme diferenciação entre as esferas de atividades doméstica e pública e onde as mulheres são isoladas umas das outras e subordinadas à autoridade de um único homem, no lar" (1979, p.53). O poder de Chen é exercido de forma absolutista. Aparentemente, é impossível contrapor-se às ordens que ele determina e, caso isso aconteça, a punição é a morte.

Um dos momentos mais emblemáticos do desconforto experimentado por Songliand é quando ela se olha no espelho e chora. O que ela vê refletido não é sedutor. Não se trata, por exemplo, do fenômeno que leva Narciso a se atirar no lago, encantado com sua própria beleza. O 
que se depreende da cena é o fato de que ela não exerce o domínio sobre si. É uma metáfora poderosa da débâcle da personagem, que será reforçada posteriormente, quando descobrir que lhe roubaram sua flauta.

\section{A flauta roubada}

O segundo ato da narrativa mostra como Songliang tenta ajustar-se à casa. A forma que ela encontra para tentar reverter sua situação de desprivilegio é tentar ser, diariamente, a escolhida pelo senhor. É um jogo difícil, que exigirá sua total disponibilidade, caso contrário, sairá perdendo. Sente isso, pela primeira vez, quando é convidada pela terceira esposa para participar de uma mesa de jogo, em companhia do médico da família e de um amigo.

Durante o jogo, um deles pergunta-lhe por que não concluiu seus estudos universitários. Ela responde que os estudos são desnecessários já que, naquela casa as mulheres são como túnicas, que o esposo tira e põe quando quer. Pouco antes havia sido avisada que o senhor regressara intempestivamente e a procurara. Como ela não estava, fora para a companhia da segunda esposa.

Em outro momento da tentativa de ajustar-se ao jogo de escolher e ser escolhida, Songliang exige do esposo que quer comer com ele a sós, em seu quarto, o que gera o protesto das outras, que alegam a quebra das regras. É uma vitória parcial, entretanto, sem maiores conseqüências.

O que desencadeará reviravoltas na trama é quando ouve alguém tocando flauta. Aproximase descobre ser o flautista o filho do seu marido, um homem jovem, provavelmente da mesma idade que ela. Têm uma breve conversa, seguida da tentativa de Songliang de encontrar a flauta que trouxera de sua casa, herança paterna. Quando não a encontra, culpa a criada que, mesmo não tendo sido a autora do roubo, de fato, trama contra ela, com a conivência da segunda esposa.

O marido então revela que foi ele que a confiscou e queimou para que ela não se distraísse de suas obrigações, mas que lhe compraria outras, se ela assim o desejasse. Ela recusa, dizendo que aquela era herança do pai e resolve vingar sua frustração na segunda esposa, cortando-lhe a orelha.

Seu ato é felicitado pela cantora de ópera, que lhe avisa que a segunda é a pior de todas e que está sempre tramando contra as demais. Aconselha-a ter um filho para que não fique em situação difícil. Songliang, então, forja uma gravidez, mas é denunciada pela criada. Dessa vez seu ódio é descontado no elo mais fraco da corrente, a criada, que é castigada até a morte. A heroína sentir-se á terrivelmente culpada pelo fim trágico da outra. 
É o momento para que perceba que, quanto mais tenta superar o infortúnio de seu casamento, mais se enreda na situação de submissão, opressão e humilhação a que todas as mulheres da casa estão submetidas. É como se tivesse sido pega por uma teia que, mais e mais, fecha-se sobre a presa que tenta escapar da armadilha.

A cena da flauta, como já havíamos comentado anteriormente, é uma metáfora poderosa de como a heroína sente seu poder ser expurgado. A flauta da história remete-nos ao mito descrito por Godelier na obra O Enigma do Dom. Tal instrumento representaria o poder das mulheres, um dia roubado pelos homens, que passam a deter a posse do instrumento proibindo-lhes o acesso. Disso decorre a posterior submissão das mulheres aos homens.

Porém, como alerta Godelier, "tais poderes permanecem fundamentalmente ligados às mulheres, é nelas que eles têm sua força originária inalienável (...) bem como seu direito de uso, já que ele não foi doado, mas adquirido pela violência, deve ser constantemente conservado pela

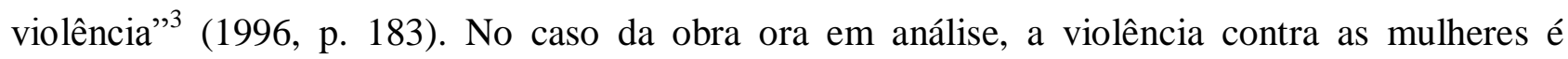
evidenciada pelos castigos físicos que lhe são impostos - visto na metáfora da Casa da Morte - e também pela forma como a força intelectual delas é minada, sendo substituída pela malediscência e pelas intrigas, atributos que, segundo reza o senso comum, são típicos do caráter feminino. Dessa forma, são incapazes de contraporem-se efetivamente ao fato de que não têm controle sequer sobre seu desejo. Songliang apercebe-se disso quando o marido, depois de procurá-la e não encontrá-la, dirigi-se à casa da segunda esposa, demonstrando à jovem que ela é um objeto ao seu dispor, o qual pode ser substituído sem qualquer prejuízo.

A estratégia adotada por Songliang é equivocada. A cada carta que joga ela sente que perdeu mais que ganhou. Não tem controle sobre si, está numa condição heterônoma. Ao discutir os conceitos de autonomia e heteronomia, Mirtes Amorim observa:

enquanto a palavra autonomia significa a legislação ou a regulação do sujeito por si mesmo, a heteronomia é a legislação ou a regulação por um outro que não o sujeito. A lei vem de fora. O homem não é o seu lócus originário. Elas são lhe impostas seja por Deus, pela razão ou pela sociedade (...) a servidão tem aí o seu fundamento. O homem obedece porque reconhece no outro autoridade para the definir o fazer e o viver (1995, p. 162).

\footnotetext{
${ }^{3}$ Ces pouvoirs restent fondamentalement attachés aux femmes, c'est en elle qu'ils ont leurs source originaire, inaliénable (...) et cet droit d'en user, parce qu'il a eté non pas donné mais acquis par la violence, doi être constamment conservé par la violence. Tradução livre
} 
Songliang, apesar do repúdio que sente pela sua condição - a qual poderíamos dizer que é idêntica à de uma concubina, já que tem que se dispor a servir, a agradar e a realizar o desejo de outrem - não ousa contrapor-se às regras, submete-se à elas quando tenta participar do jogo de intrigas e luta pela posse do poder, que mobiliza as mulheres da casa. Nem a criada escapa da rede, já que sonha em ser uma das esposas e assim enxerga em Songliang uma rival. Entretanto, Songliang não se submete com resignação, como faz a esposa mais velha, não dispõe do poder maquiavélico da segunda, nem está imersa no papel de sedutora que a terceira desempenha e, finalmente, não tem a obstinação demonstrada pela criada. Ela ocupa o não-lugar. Sua vontade movimenta-se como um pêndulo. Oscila ao sabor dos caprichos dos outros. O espelho que refletiu sua imagem na primeira noite em que passou no castelo está cada vez mais embaçado e ameaça estilhaçar-se. Sua imagem continuará fragmentando-se à medida em que sentir diminuir sua autonomia.

Uma narrativa lenta, pontuada por imagens soberbas do exterior do castelo, pela riqueza dos adereços de cena, pelo luxo do figurino e por tomadas em primeiro plano do belíssimo rosto de Songliang, pontuarão o desfecho trágico que se anuncia.

\section{Loucura e morte}

O terceiro ato marca a evolução do estado depressivo da heroína. O cenário exterior é tomado pela luz branca da neve que cai incessantemente nos arredores do palácio. A metáfora do frio, da ausência do verde e das árvores desnudas condiz com a condição de Songliang. Quando é avisada da morte da criada, ela assume a culpa para si e isola-se mais e mais. No dia do seu aniversário embebeda-se, argumenta com quem tenta tirá-la do ostracismo que é melhor morrer do que sofrer.

O estado emocional de Songliang continua a deteriorar-se: embriaga-se continuamente o que termina por fazê-la delatar à segunda esposa que a terceira tem um amante. Numa manhã, quando acorda, percebe que estão levando a terceira esposa para o quarto da torre. Uma criada lhe diz que, graças à informação que dera, descobriram que a cantora tinha um amante. Songliang percebe o que provocara e tenta deter os guardas, porém acaba presenciando o assassinato dela. Denuncia o crime ao senhor, mas é acusada de louca.

O cenário exterior muda mais uma vez com a chegada do verão. O clã dos Chen incorpora a quinta esposa. Ela chega radiante em sua juventude e beleza. Aponta para Songliang, que caminha 
sozinha em meio às lanternas vermelhas e pergunta quem é ela. Avisam-na que era a quarta esposa até o momento em que enlouqueceu.

Consumada a tragédia, fica evidente que não bastou à heroína um conhecimento maior do que o das outras esposas para que pudesse enfrentar o poder patriarcal. Observe-se que, em vários momentos, ao longo da narrativa, as pessoas que rodeavam Songliang questionaram-lhe sobre os seus estudos, sugerindo-lhe, inclusive, que eles poderiam ser utilizados como um trunfo. É o que o somos levados a supor inicialmente. À medida que a história avança, entretanto, o fato de Songliang ser instruída não diminui sua fragilidade diante da opressão do masculino e das intrigas que a disputa pelo poder doméstico acarreta.

O poder, aqui não é encarado como uma instância única, que se exerce de forma verticalizada no seio da sociedade. Segundo Foucault “Os poderes não são a derivação, a conseqüência de um poder central. (...) a função primordial dos poderes não é proibirem, mas serem produtores de uma eficiência, de uma atitude”. (FOUCAULT, 1976/1979, p.187). É algo porque se luta constantemente, algo que se almeja e que pode ser observado em diferentes situações e diferentes relações, espalhando-se como uma rede, a qual ele dá o nome de malhas do poder. Ademais, é exercido, na maioria das vezes, pela adesão voluntária dos sujeitos, os quais estão imersos em práticas simbólicas invisíveis, às quais aprendem a assujeitarem-se desde o momento em que nascem, em um contínuo aprendizado, marcado não apenas por perdas, mas também por ganhos.

Dessa forma, já não soa tão estranho as intrigas que movem as personagens do filme pela disputa do poder doméstico. Afinal, ele traz privilégios, confere prestígio a quem o detém, causa inveja aos que não o possuem. Pode-se alegar que se trata de um poder ínfimo, frágil, já que a figura masculina, no caso o marido, é chamado para colocar ordem na casa sempre que os conflitos estão prestes a superarem os limites do aceitável. Entretanto, é atraente, já que possibilita privilégios a quem o detém e, por isso, causa tanta cobiça.

O filme explora uma relação assimétrica entre os gêneros masculino e feminino, realidade essa que levou estudiosas identificadas com a psicanálise a afirmarem que

a figura materna, ou feminino, é aquilo que se subtrae, a falta, o Outro, o que se submete no inconsciente, formando-o. Por sua parte, a figura paterna, ou seja, o masculino, passa a ser identificado com o falo, o que produz o gozo mas também sabe cortá-lo, interditá-lo, em nome da lei: o discriminador, e também o teórico, o filósofo e o ideólogo, por ser capaz de outorgar os nomes, lugares e papéis, criando 
o mundo com seus objetos e pessoas carregados de valor e sentido (Segato, 1993, p.7).

Tal concepção acerca dos gêneros, é preciso que se diga, está associada a um tipo de relação que exige uma estrutura familiar tradicional, baseada na monogamia (o que no filme vale, ao menos, para as mulheres), na heterossexualidade, na rígida divisão Erro! Nenhuma entrada de índice remissivo foi encontrada. variações familiares existentes na sociedade, particularmente na contemporânea.

Também deve ser vista com cuidado, pois como afirma Lauretis, o que a psicanálise, inicialmente, criou para explicar como uma atitude, resultante de uma ficção ou uma fantasia produzida no inconsciente dos indivíduos, muitas vezes, é tomada como uma verdade absoluta, ontológica. Butler observa que as injunções de gênero não podem ser vistas apenas do ponto de vista do desejo, já que envolvem questões mais profundas, o que a levou a criar a noção de sexogênero, duas instâncias inseparáveis. Esclarecido que não acreditamos ser possível tomar toda e qualquer relação de sexo-gênero sob a perspectiva da psicanálise lacaniana, creio que para o caso da análise de Lanternas Vermelhas ela é, parcialmente, conveniente, visto que elucida algumas injunções presentes na narrativa.

No filme o masculino exerce o papel de regulador, o que pode ser exemplificado em cenas diversas: quando Songliang e a criada enfrentam-se, nas crises surgidas entre as esposas ou quando é descoberta a traição da terceira esposa. O esposo demonstra nessas situações que é ele que possui o comando, que legisla e que pune, segundo suas conveniências. Não está colocada a possibilidade de contravenção para o feminino ou de negação do status quo masculino.

A disputa pelo poder doméstico também pode ser percebida sob outro ângulo. Indica que o estabelecimento do gênero é sempre o estabelecimento do poder. Os gêneros não estão imersos em uma disputa ostensiva, marcada pelo dualismo entre dominador e dominado. Ninguém detém o poder de forma inexorável. Como disséramos, o poder é algo pelo que se luta continuamente. As personagens femininas também não estão imersas na inocência e tomadas pelo desejo (conforme depreende-se dos lances arriscados que elas fazem em busca do exercício do poder) nem o homem detém totalmente o controle. Muitas vezes, ele é enganado, seja quando elas forjam uma gravidez ou quando mantém um amante sob as barbas do patriarca, sem que este sequer desconfie da traição.

Butler, quando explica como as pessoas elegem o gênero - é preciso observar que para essa autora o gênero não é uma imposição da natureza - afirma que tal atitude não se faz pela 
advertência de um momento, mas sim por um processo laborioso: "chegar a ser gênero é um processo, impulsivo, ainda que cuidadoso, de interpretar uma realidade cultural carregada de sanções, tabus e prescrições”. (1992, p. 198). O fato é que o processo de eleição ou adoção de um gênero (admitindo-se aqui a multiplicidade dos que existem de fato) é essencial à formação da identidade. Não há como escapar-lhe. "na medida em que a existência social requer uma afinidade de gênero que não seja ambígua, não é possível existir em sentido socialmente significativo fora das normas de gênero estabelecidas" (BUTLER, 1992, p. 198).

Na opinião das feministas lacanianas, tais como Gayle Rubin, estar no feminino excluiria o exercício do poder, o qual estaria sempre sob domínio do masculino. Ao retomar a obra de Irigaray, Margareth Whitford observa que a autora tenta criticar a ênfase no poder da determinação simbólica dos lacanianos. Essa crítica envolve a discussão acerca das conseqüências da não simbolização da relação mãe-filha. "Ao descrever essa relação como não-simbolizada, Irigaray quer dizer que daquela relação se registra uma ausência de representações lingüísticas, sociais, culturais, icônicas, teóricas, míticas, religiosas ou de qualquer outro tipo" (WHITFORD, 1997, p.148). O resultado disso seriam as dificuldades demonstradas pelas mulheres de representarem a si mesmas. Para a prática do feminismo, observa Whitford, a questão é "como construir uma socialidade feminina, um simbólico feminino e um contrato social feminino: uma relação horizontal entre mulheres, para que as mulheres não sejam deixadas nesse estado de abandono" (WHITFORD, 1997, p. 149).

É comum ouvirmos comentários jocosos sobre a suposta rivalidade existente entre as mulheres. Isso seria o resultado da incapacidade feminina de solidarizar-se e estabelecer relações de cumplicidade e de companheirismo com seu próprio gênero. Por outro lado, explicaria o pendor para a desonestidade, para as intrigas e para a malediscência. No filme de Zhang Yimou estas intrigas estão retratadas na disputa que as esposas travam entre si. É uma luta que as mobiliza de tal forma que as impede de unirem-se para refletir sobre a situação de opressão em que vivem e sobre as estratégias que deveriam ser elaboradas para que elas fossem alteradas.

Irigaray, observa Whitford, percebe nisto uma manifestação do que as mulheres sofrem pela não simbolização da relação mãe/filha. Dessa forma, cita-a nominalmente para caracterizar a necessidade de uma outra simbolização:

É necessário que seja criado um simbolismo entre as mulheres para que possa existir o amor entre elas. Esse amor, em todo o caso, só é possível, no momento, entre as mulheres que podem falar umas com as outras. Sem aquele intervalo de trocas ou de palavras, ou de gestos, as paixões contra as mulheres se manifestam de maneira bastante cruel". (IRIGARAY, apud 1997, p. 153). 
A crueldade que as mulheres manifestam uma contra as outras em Lanternas Vermelhas levam-nas a autodestruição. O marido, por sua vez, permanece impune nos seus atos de crueldade. Quando a terceira e a quarta esposa são destruídas, rapidamente providenciam-se suas substituições, por uma quinta mulher, tão jovem e tão bela quanto as suas antecessoras. $O$ filme chega a ser cruel na forma como é narrada a incapacidade feminina de pensar sobre sua condição de forma racional e, consequentemente, de alterá-la.

Quando refletimos sobre essa dificuldade, é importante que se observe que ela não é imutável. Irigaray, com suas colocações sobre a necessidade de se criar uma gramática feminina, uma simbolização, que permita às mulheres saírem do estado fusional de origem, permitindo-lhes a separação entre os estados de mãe e de mulher, dá um salto qualitativo no estudo de gênero de origem psicanalítica. Whitford comenta, sobre tais avanços "mais que minimizar a diferença sexual, considera que o único modo de avançar é afirmá-lo; e que o estado da mulher só poderia ser fundamentalmente alterado mediante a criação de um poderoso simbólico feminino que representasse o outro contra os efeitos onipresentes do imaginário masculino" (1997: 164).

Essas colocações ajudam-nos a compreender um pouco mais sobre as dificuldades da protagonista da obra em questão para levantar-se e, simplesmente, abandonar a casa em que as mulheres tem o valor equiparado "ao de cães e gatos ou ratos, certamente não de seres humanos", de acordo com a definição formulada pela terceira esposa diante da indagação da quarta sobre qual o valor delas naquele espaço.

\section{Considerações finais}

Mais uma vez, é preciso observar que tomamos o filme como uma metáfora das relações de gênero de um seguimento social específico: o de mulheres brancas, heterossexuais, classes média e alta, casadas ou casadoiras. Se considerarmos pesquisa recente feita pela revista $\mathbf{E ́ p o c a}^{4}$ de que uma porcentagem grande de brasileiras, situadas na faixa etária dos 20, ainda almeja situação similar casar, ter filhos, cuidar do lar - não é possível desprezar que os arranjos de gênero dessa categoria ainda precisam ser vistos com atenção e não desprezados. Afinal, ainda que o paroxismo do senhor feudal que detém o poder de vida e de morte sobre suas mulheres deva ser visto como uma ficção, não pode ser excluído como metáfora de relações contemporâneas nas quais prevalecem o

\footnotetext{
4 "O que são e o que querem as mulheres de 20" in Revista Época. Rio de Janeiro, Ed. Globo, 6/09/2010. no. 642, p.66 a 73.
} 
predomínio masculino sobre o casal o que, muitas vezes, pode culminar em mulheres frustradas, maltratadas psicológica e/ou fisicamente.

Persiste a dúvida, porque elas submetem-se? não é possível acreditar em propensão para a infelicidade, mas, quem sabe, supor que, ao procurar a segurança financeira e emocional, supostamente proporcionados pelo casamento, decidam-se, muitas vezes, ainda que inconscientemente, por abrir mão da dignidade, da autonomia e do controle sobre o seu desejo. A psicanálise sozinha não é capaz de responder a tais indagações, mas não pode ser desprezada do ponto de vista do que ocorre no interior de milhares de mulheres que estão ao nosso redor.

Acreditamos que as elaborações feministas em conjunto, como algumas das relacionadas no texto, são as mais indicadas para que pensemos novas práticas afetivas, novos formas de relacionamento, que privilegiem a solidariedade, a confiança mútua e o respeito entre os gêneros.

\section{Fonte}

YIMOU, Zhang. Lanternas Vermelhas. Cannes Home Vídeo, S.P, 1991.

\section{Referências}

AMORIM, Mirtes Miriam. Labirintos da autonomia: a utopia socialista e o imaginário em Cornelius Castoriadis. Fortaleza: Edições UFC, 1995.

BUTLER, Judith. Variaciones Sobre Sexo y Gênero. Beauvoir, Wittig y Foucault. In: BENHABIB, Seyla; CORNELLA, Drucilla (Orgs.). Teoría feminista y teoría crítica. Espanha: Edions Alfons El Magnanim, 1994.

. Problemas de gênero. Rio de Janeiro: Civilização Brasileira, 2003.

FOUCAULT, Michel. Dits et Écrits III. Paris: Éditions Gallimard, 1976/1979.

GODELIER, Maurice. L' Enigme du Don, Paris: Arthème Fayard, 1996.

HALL, Stuart. Quem Precisa de Identidade? In: SILVA, Tomaz Tadeu da. (Org.). Identidade e diferença. Petrópolis, RJ, Vozes, 2000.

KELLNER, Douglas. A cultura da mídia. Bauru, SP: EDUSC, 2001.

LACAN, Jacques. Escritos. 4. ed. São Paulo: Perspectiva, 1996.

ROSALDO, Michelle Zimbalist e LAMPHERE, Louise. Introdução. In: (Orgs.). A mulher, a cultura e a sociedade. Rio de Janeiro: Paz e Terra, 1979.

ROSALDO, Michelle Zimbalist e LAMPHERE, Louise. A mulher, a cultura e a sociedade: uma revisão teórica. In: . (Orgs.). A mulher, a cultura e a sociedade. Rio de Janeiro: Paz e Terra, 1979.

RUBIN, Gayle. The traffic in women: notes on the political economy of sex. In: REITER, Rayna B. (Org.). Toward and anthropology of women. New York: Monthly Review Press, 1975. 
SEGATO, Rita Laura. A natureza do gênero na psicanálise e na antropologia. UnB, 1993. (Série Antropologia, 146.).

SILVERMAN, Kaja. Male subjectivity at the margins. New York and London: Rotledge, 1992. STORE, V. R. Eliana. Cultura, imaginação e conhecimento: a educação e a formalização da experiência. São Paulo: Unicamp, 1993.

WHITFORD, Margaret. Releitura de Irigaray. In: BRENAN, Teresa (Org.). Para além do falo: uma crítica a Lacan do ponto de vista da mulher. Rio de Janeiro: Rosa dos Tempos, 1997. 